Revista Brasileira de Bioética 2007; 3 (3): 406-09

Resenha de livros

Esta seção destina-se à apresentação de resenhas de livros de interesse

para a bioética

\title{
Ética na pesquisa em saúde: avanços e desafios
}

\section{GUILHEM D; TICKER F. (editores)}

Brasília: Editoras Letras Livres/ UnB, 2007. ISBN: 85-98070-14-9

85-23009-13-2

Ética na pesquisa em saúde: avanços e desafios é o segundo volume da coleção Ética em Pesquisa publicada pelas editoras Letras Livres e Universidade de Brasília (UnB). Essa coleção tem por objetivo discutir e apresentar vários pontos de vista a respeito das questões éticas envolvidas nas realizações de pesquisas clínicas, biomédicas e sociais em saúde. Os editores apresentam como referências a Resolução 196/96 e a Declaração de Helsinque, considerando que a história dos debates sobre a ética em pesquisas envolvendo seres humanos teve como marco inicial o Código de Nuremberg.

O processo de globalização da pesquisa em saúde, associado às questões econômicas e a vulnerabilidade de países em desenvolvimento como lócus de estudo, de produção de conhecimento e de desenvolvimento de produtos, justifica o crescente interesse dos autores pelo tema da ética em pesquisa. Na Plataforma Lattes, do Conselho Nacional de Desenvolvimento Cientifico e Tecnológico (CNPq), estão registrados 56 grupos de pesquisa em ciências da saúde; 72 em ciên-cias biológicas, 51 em ciências humanas e 48 em ciências sociais aplicadas. Esse contingente de pesquisadores e estudantes, desenvolve algum tipo de investigação envolvendo seres humanos. Entretanto, esse progresso não tem sido acompanhado adequadamente pelo processo de formação acadêmica dos pesquisadores, ocasionando um descompasso entre a lógica avaliativa das pesquisas e a capacitação ética dos investigadores quanto à cultura de direitos humanos e a equidade em suas atividades.

O livro está dividido em três partes, de acordo com o tipo de 
pesquisa: com intervenção, sem intervenção e com a utilização de animais não-humanos. Na primeira delas, Ética em pesquisa - estudos com intervenção, são discutidos os ensaios clínicos por Gustavo Adolfo Sierra Romero, que contextualiza a necessidade de realizar pesquisa clínica à luz da reflexão ética. Segundo o autor, a falta de conhecimento da melhor alternativa para tratar ou prevenir uma doença justifica quase inevitavelmente a realização de um experimento, no qual indivíduos serão expostos a uma intervenção, cujos efeitos, pelo menos os definitivos, são desconhecidos. Para o desenvolvimento de um ensaio clínico, o produto a ser testado deverá ter o potencial de causar um efeito melhor que o tratamento convencional disponível; esta informação provém da pesquisa pré-clínica, fase em que pesquisadores obtém informações de experimentos celulares e animais, entre outros, para garantir razoavelmente o início seguro da pesquisa em humanos.

Os princípios metodológicos que garantem a consistência científica dos ensaios clínicos e cumpram com os preceitos éticos de nãomaleficência, beneficência, eqüidade e justiça, incluem basicamente os aspectos relativos ao processo de alocação randômica, ao uso de controles concorrentes, aos critérios de inclusão, a definição de esquemas terapêuticos, a aferição objetiva dos desfechos e a estratégia de análise estatística dos dados. A proposta de ensaios em humanos impõe a participação voluntária e consentida de indivíduos, sendo o consentimento livre e esclarecido a forma de garantir o respeito e a autonomia dos participantes. Portanto, ele deve cumprir com exigência rigorosa de esclarecimento dos riscos e de todas as informações relevantes da pesquisa

Na segunda parte, Ética em pesquisa - estudos sem intervenção, é discutida a pesquisa qualitativa em saúde e suas implicações éticas. Os autores, Marcelo Medeiros, Denize Bouttelet Munari, Ana Lucia Queiroz Bezerra e Maria Alves Barbosa, discorrem sobre as implicações éticas da pesquisa qualitativa, partindo do princípio que será iniciado um processo de pesquisa-entrada no campo, interação entre pesquisadores e participantes, coleta de dados, devolução dos resultados, saída do campo e divulgação dos resultados. Os autores mostram que o respeito aos aspectos éticos podem minimizar as dificuldades inerentes à pesquisa qualitativa. O respeito ao princípio da 
autonomia, tende a garantir que a inclusão do participante seja - de fato - voluntária. Tomar em consideração o princípio da beneficência colabora para que se evite danos ou prejuízos, incluindo a quebra da confidencialidade. Levar em conta o princípio da justiça, pode impedir a exploração e o abuso dos participantes.

A abordagem qualitativa na pesquisa em saúde possibilita conhecer o significado da experiência das pessoas no processo saúdedoença e levantar os padrões de comportamento adotados por elas, contribuindo, assim, para possível mudança de comportamento, interferindo na qualidade de vida dos indivíduos e das comunidades.

A terceira parte, Pesquisa com animais não-humanos, trata dos aspectos éticos da experimentação com animais não-humanos e tem como autores Ronald Gerardo Garcia Gómez e Carlos Alberto Bezerra Tomaz. Os autores argumentam que toda experimentação com seres humanos deve ser, obrigatoriamente, precedida pela experimentação com animais não humanos. Os testes com animais não-humanos têm o objetivo de revelar os efeitos maiores, como falha hepática, insuficiência respiratória, elevação da pressão arterial, reações durante a gestação. Os princípios éticos na experimentação animal baseiam-se em três critérios: existir forte justificação para realizá-la; quando os benefícios são maiores que os riscos e o sofrimento produzido; quando a capacidade para sentir dor das espécies animais é menor.

Cabe observar que o livro é importante para formação de jovens pesquisadores, incorporando a ética ao saber cientifico, estimulando o pensamento crítico, a reflexão e a busca de novas perspectivas sobre cada tema, desenvolvendo competências para realizar julgamentos e tomar decisões sobre os problemas morais da realização de pesquisas que envolvam tanto seres humanos como animais não-humanos. Os autores convidados refletem sobre as implicações éticas de vários tipos de pesquisas desenvolvidas com seres humanos, fundamentadas em documentos que regulamentam a atividade de pesquisas clínicas, biomédicas e sociais em saúde

A vulnerabilidade de países em desenvolvimento é um dos grandes desafios da ética na pesquisa em saúde. Se, por um lado, a produção de conhecimento, como a descoberta de novas formas de tratamento e prevenção de doenças, representam um grande avanço, questões éticas como o respeito pelas pessoas (autonomia), a beneficência e a 
Revista Brasileira de Bioética 2007; 3 (3): 406-09

justiça são princípios que ainda representam desafios.

\section{Dalma Alves Pereira}

Universidade Federal de Goiás e Hospital das Clínicas de Goiânia, Goiás, Brasil.

dalmaalvespereira@hotmail.com 